\title{
Severe metabolic alkalosis, hypokalemia, and respiratory acidosis induced by the Chinese herbal medicine yokukansan in an elderly patient with muscle weakness and drowsiness
}

\author{
Shunsuke Yamada $\cdot$ Masanori Tokumoto $\cdot$ Yasuo Kansui • \\ Yoshinobu Wakisaka • Yuji Uchizono $\cdot$ Kazuhiko Tsuruya • \\ Hiroaki Ooboshi
}

Received: 20 May 2012/ Accepted: 24 July 2012/Published online: 12 September 2012

(C) Japanese Society of Nephrology 2012

\begin{abstract}
Yokukansan is a Chinese herbal medicine containing licorice that has been shown to alleviate the behavioral and psychological symptoms of Alzheimer's disease, with few adverse effects. Increasing numbers of patients with Alzheimer's disease in Japan are now being treated with this drug. However, yokukansan should be used with caution because of its potential to induce pseudoaldosteronism through the inhibition of 11-betahydroxysteroid dehydrogenase type 2 , which metabolizes cortisol into cortisone. We present the case of an 88-yearold woman with a history of Alzheimer's disease who was transferred to our emergency department because of drowsiness, anorexia, and muscle weakness. Her blood pressure was 168/90 mmHg. Laboratory data showed serum potassium of $1.9 \mathrm{mmol} / \mathrm{l}$, metabolic alkalosis $(\mathrm{pH} 7.54$; $\mathrm{HCO}_{3}^{-}, 50.5 \mathrm{mmol} / \mathrm{l}$; chloride, $81 \mathrm{mmol} / \mathrm{l}$; sodium, 140 $\mathrm{mmol} / \mathrm{l})$, and respiratory disorders $\left(\mathrm{pCO}_{2}, 60.5 \mathrm{mmHg} ; \mathrm{pO}_{2}\right.$, $63.8 \mathrm{mmHg}$ ). Plasma renin activity and aldosterone concentration were suppressed, and urinary potassium excretion was $22 \mathrm{mmol} / \mathrm{l}$ (calculated transtubular potassium gradient 12.9). An electrocardiogram showed flat $T$-waves and U-waves with ventricular premature contractions.
\end{abstract}

S. Yamada - M. Tokumoto · Y. Kansui - Y. Wakisaka ·

Y. Uchizono $\cdot$ H. Ooboshi

Division of Internal Medicine, Fukuoka Dental College,

2-15-1 Tamura, Sawara-Ku, Fukuoka 814-0193, Japan

S. Yamada $(\bowtie)$

Department of Medicine and Clinical Science,

Kyushu University, Fukuoka, Japan

e-mail: ana65641@nifty.com

K. Tsuruya

Integrated Therapy for Chronic Kidney Disease, Graduate

School of Medical Sciences, Kyushu University, Fukuoka, Japan
Echocardiography denied volume depletion. Medical interview disclosed that she had been treated with a Chinese herbal medicine (yokukansan) containing licorice. The final diagnosis was pseudoaldosteronism and respiratory acidosis induced by licorice. Hypokalemia, metabolic alkalosis, and respiratory acidosis all subsided shortly after the discontinuation of yokukansan and initiation of intravenous potassium replacement. This case highlights the need for nephrologists to consider the possible involvement of Chinese herbal medicines, including yokukansan, when they encounter hypokalemia in elderly patients.

Keywords Herbal medicine $\cdot$ Hypokalemia $\cdot$ Metabolic alkalosis · Licorice · Yokukansan

\section{Introduction}

Hypokalemia is an important electrolyte disorder occasionally seen in elderly patients [1]. The serum potassium (K) level is determined mainly by the balance among oral intake, distribution, and excretion via the kidney and the gastrointestinal tract [2]. Although hypokalemia in elderly patients is often attributed to decreased $\mathrm{K}$ intake or $\mathrm{K}$ loss through the gastrointestinal tract, it can be caused by urinary $\mathrm{K}$ loss as a side effect of drug administration [3-6].

Several investigators have recently shown that the Chinese herbal medicine yokukansan can alleviate the behavioral and psychological symptoms of dementia (BPSD), such as hallucinations, delusions, agitation, aggression, and wandering, in patients with Alzheimer's disease, with few side effects [7-9]. The numbers of elderly people with Alzheimer's disease have been increasing, and drugs that can safely and effectively mitigate BPSD are, therefore, in demand. However, some herbal medicines, including 
yokukansan, contain licorice and can occasionally cause pseudoaldosteronism by inhibiting endogenous 11-betahydroxysteroid dehydrogenase type $2(11 \beta$-HSD2), resulting in mild to severe hypokalemia and metabolic alkalosis $[5,6]$.

We describe here the case of an elderly patient treated with yokukansan, who developed severe hypokalemia, metabolic alkalosis, and respiratory acidosis related to muscle weakness.

\section{Case report}

An 88-year-old woman was transferred to our hospital because of drowsiness, muscle weakness, and anorexia. She had been receiving care at a nursing home for the last 3 years because of worsening Alzheimer's disease. Her medical history included replacement of bilateral femoral heads at ages 81 and 83 years, respectively. Six months before admission, yokukansan treatment was initiated to control BPSD related to Alzheimer's disease. However,
3 weeks after the start of yokukansan treatment, she developed constipation, and a laxative was administered. Her serum $\mathrm{K}$ and chloride $(\mathrm{Cl})$ levels just prior to starting yokukansan treatment were 4.2 and $101 \mathrm{mmol} / \mathrm{l}$, respectively.

On admission, she was somnolent. Her height was $154 \mathrm{~cm}$ and body weight was $38.4 \mathrm{~kg}$. Her blood pressure was $168 / 90 \mathrm{mmHg}$, heart rate 88 beats per minute, body temperature $37.8^{\circ} \mathrm{C}$, and respiratory rate $10 / \mathrm{min}$. Physical examination revealed that both patellar and plantar reflex were attenuated, and her respiration was shallow. Muscle strength in her limbs was also weakened. Pretibial pitting edema was observed bilaterally. Her biochemical parameters and urinary findings are summarized in Table 1 . Serum sodium (Na) was $140 \mathrm{mmol} / \mathrm{l} ; \quad \mathrm{K}, 1.9 \mathrm{mmol} / \mathrm{l} ; \mathrm{Cl}$, $81 \mathrm{mmol} / \mathrm{l}$; and C-reactive protein, $6.0 \mathrm{mg} / \mathrm{dl}$. Urinary levels of $\mathrm{Na}, \mathrm{K}$, and $\mathrm{Cl}$ were 45,22 , and $43 \mathrm{mmol} / \mathrm{l}$, respectively. Urinalysis revealed bacteriuria and leukocyturia, indicating concomitant urinary tract infection. Arterial blood gas analysis revealed $\mathrm{pH} 7.54 ; \mathrm{pO}_{2}, 63.8 \mathrm{mmHg}$ $\left(\mathrm{O}_{2} 0.5 \mathrm{l} / \mathrm{min}\right.$, nasal cannula); $\mathrm{pCO}_{2}, 60.5 \mathrm{mmHg}$; and $\mathrm{HCO}_{3}^{-}, 50.5 \mathrm{mmol} / \mathrm{l}$. Plasma renin activity and aldosterone
Table 1 Laboratory data on admission

Serum was collected after fasting in the morning:

ACTH adrenocorticotropic hormone, $H D L$ high-density lipoprotein, $L D L$ low-density lipoprotein, $P A C$ plasma aldosterone concentration, $P R A$ plasma renin activity, TSH thyroid-stimulating hormone

\begin{tabular}{|c|c|c|c|}
\hline \multicolumn{2}{|l|}{ Complete blood count } & \multicolumn{2}{|l|}{ Urinalysis and urinary sediment } \\
\hline White blood cell count, $/ \mu \mathrm{l}$ & 6900 & $\mathrm{pH}$ (dipstick) & 7.0 \\
\hline Hemoglobin, g/dl & 12.2 & Specific gravity (dipstick) & 1.010 \\
\hline Platelets, $\times 10^{4} / \mu 1$ & 22.7 & Protein (dipstick) & \pm \\
\hline Biochemistry & & Hematuria (dipstick) & Negative \\
\hline Total protein, g/dl & 5.4 & Bilirubin & Negative \\
\hline Albumin, g/dL & 3.0 & Ketone & Negative \\
\hline Total bilirubin, $\mathrm{mg} / \mathrm{dl}$ & 1.6 & Bacteria & $3 \pm$ \\
\hline Aspartate aminotransferase, U/l & 23 & Red blood cell, high-power field & $1-4$ \\
\hline Alanine aminotransferase, U/l & 14 & White blood cell, high-power field & $30-49$ \\
\hline Lactate dehydrogenase, U/1 & 205 & Epithelial cell, high-power field & $10-19$ \\
\hline Creatine phosphokinase, U/l & 12 & Urinary biochemistry & \\
\hline Blood urea nitrogen, mg/dl & 10.5 & Sodium, mmol/l & 45 \\
\hline Creatinine, mg/dl & 0.62 & Potassium, mmol/1 & 22 \\
\hline Uric acid, mg/dl & 3.5 & Chloride, $\mathrm{mmol} / \mathrm{l}$ & 43 \\
\hline Sodium, mmol/l & 140 & Urine osmolarity, $\mathrm{mOsmol} / \mathrm{kgH}_{2} \mathrm{O}$ & 263 \\
\hline Potassium, mmol/l & 1.9 & Endocrinology & \\
\hline Chloride, $\mathrm{mmol} / \mathrm{l}$ & 81 & PRA, ng/ml/h & 0.3 \\
\hline Magnesium, mg/dl & 2.6 & $\mathrm{PAC}, \mathrm{pg} / \mathrm{ml}$ & 17.8 \\
\hline Calcium, mg/dl & 8.6 & TSH (serum), $\mu \mathrm{U} / \mathrm{ml}$ & 1.33 \\
\hline Phosphorus, mg/dl & 4.0 & Free T4 (serum), ng/dl & 1.23 \\
\hline Triglyceride, $\mathrm{mg} / \mathrm{dl}$ & 69 & ACTH (plasma), pg/ml & 59 \\
\hline Total cholesterol, mg/dl & 194 & Cortisol (serum), $\mu \mathrm{g} / \mathrm{ml}$ & 18.4 \\
\hline LDL-cholesterol, mg/dl & 109 & Cortisol (urine), $\mu \mathrm{g} / \mathrm{day}$ & 122 \\
\hline HDL-cholesterol, mg/dl & 54 & Blood gas analysis & \\
\hline C-reactive protein, $\mathrm{mg} / \mathrm{dl}$ & 6.3 & $\mathrm{pH}$ & 7.54 \\
\hline Glucose, mg/dl & 92 & $\mathrm{pO}_{2}\left(\mathrm{O}_{2} 0.5 \mathrm{l} / \mathrm{min}\right.$, nasal cannula $), \mathrm{mmHg}$ & 63.8 \\
\hline $\mathrm{HbA1c}, \%$ & 4.5 & $\mathrm{pCO}_{2}, \mathrm{mmHg}$ & 60.5 \\
\hline Plasma osmolarity, mOsmol/ $\mathrm{kgH}_{2} \mathrm{O}$ & 275 & $\mathrm{HCO}_{3}^{-}, \mathrm{mmol} / \mathrm{l}$ & 50.5 \\
\hline
\end{tabular}


Fig. 1 Computed tomography of $\mathbf{a}$ the chest and $\mathbf{b}$ the abdomen on admission
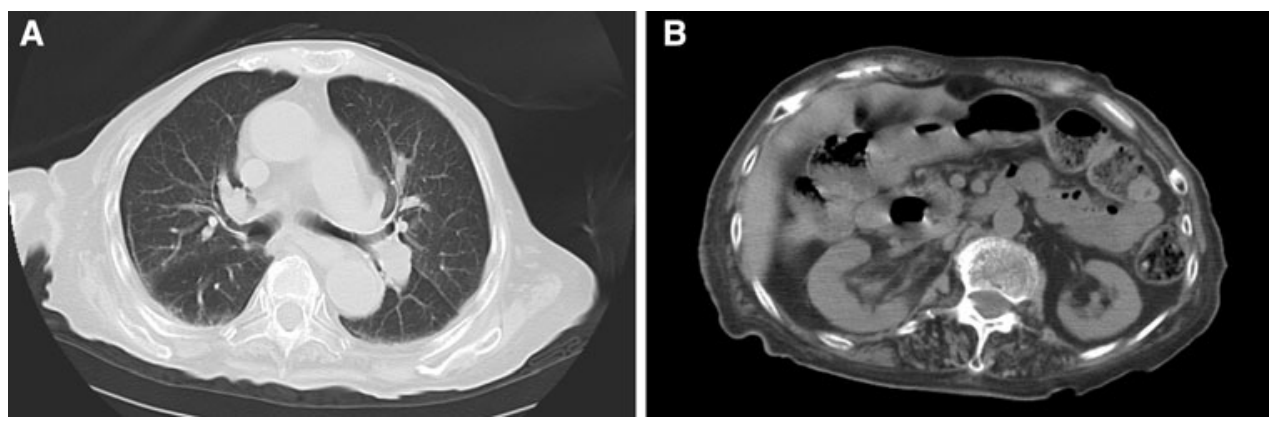

Fig. 2 Clinical course during hospitalization. $\mathrm{HCO}_{3}^{-}$ bicarbonate, $i v$ intravenous, $K$ potassium, $S B P$ systolic blood pressure, $D B P$ diastolic blood pressure

\begin{tabular}{|c|c|c|c|c|c|c|c|c|c|c|c|c|c|c|}
\hline $\mathrm{SBP}(\mathrm{mmHg})$ & 178 & 174 & 180 & 194 & 190 & 170 & 174 & 160 & 160 & 158 & 146 & 140 & 138 & 140 \\
\hline DBP(mmHg) & 92 & 88 & 92 & 90 & 94 & 92 & 90 & 86 & 88 & 82 & 86 & 82 & 78 & 76 \\
\hline Blood pH & 7.56 & 7.55 & 7.51 & & & 7.48 & & & & 7.45 & & & 7.41 & 7.40 \\
\hline $\begin{array}{c}\text { Urine } \mathrm{K} \\
(\mathrm{mmol} / \mathrm{day})\end{array}$ & 23 & & & & & 32 & & & & 45 & & & & 46 \\
\hline
\end{tabular}

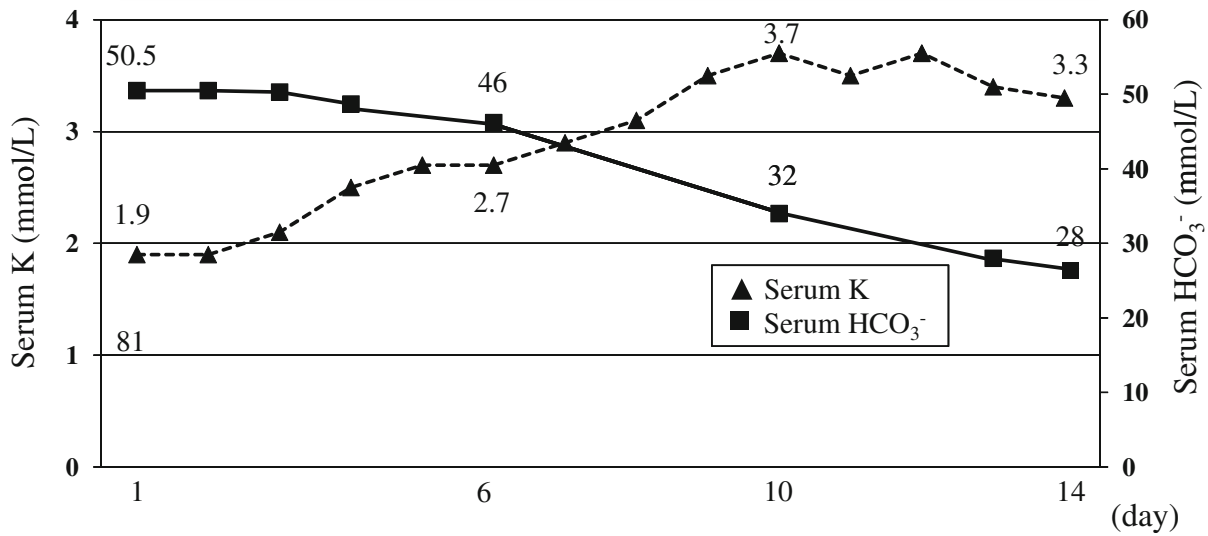

concentration were $0.3 \mathrm{ng} / \mathrm{ml} / \mathrm{h}$ (normal range; 0.3-2.9) and $17.8 \mathrm{pg} / \mathrm{ml}$ (normal range; 35.7-240), respectively. The calculated transtubular K gradient was 12.9. Endocrinological study revealed thyroid-stimulating hormone of $1.33 \mu \mathrm{g} / \mathrm{ml}$, thyroxin of $1.23 \mu / \mathrm{ml}$, adrenocorticotropic hormone of $59 \mathrm{pg} / \mathrm{ml}$, and cortisol of $18.4 \mu \mathrm{g} / \mathrm{ml}$. Urinary cortisol was $122 \mu \mathrm{g} /$ day (normal range; 26-187). Echocardiography revealed preserved left ventricular systolic function and an inferior vena cava diameter of $15 \mathrm{~mm}$. An electrocardiogram showed flat $\mathrm{T}$-waves and U-waves in leads V2-V5 and ventricular premature contractions. The corrected QT interval was 485 ms. Computed tomography showed neither infiltrative lesions nor lung diseases, including chronic obstructive pulmonary disease (Fig. 1a). There was no mass in the adrenal glands and no signs of calcium deposition or calcinosis in the kidney (Fig. 1b). Her medications were oxidized magnesium $1.5 \mathrm{~g} /$ day, alfacalcidol $0.5 \mu \mathrm{g} /$ day, and brotizolam $0.25 \mathrm{mg} /$ day. However, she had also been treated with yokukansan $7.5 \mathrm{~g} / \mathrm{day}$, containing $4.5 \mathrm{~g}$ of licorice, and was, therefore, finally diagnosed with licorice-induced pseudoaldosteronism, as a result of the inhibition of $11 \beta$-HSD2 by the licorice.

Figure 2 summarizes the patient's clinical course during hospitalization. The administration of yokukansan was discontinued and intravenous $\mathrm{K}$ replacement was initiated from the first hospital day. The supplemental $\mathrm{K}$ dose was adjusted according to her daily serum and urinary $\mathrm{K}$ levels, ranging from 30 to $80 \mathrm{mmol} /$ day, until the 11th hospital day. She was also treated with antibiotics for a coincident urinary tract infection, which subsided after 7 days of treatment. Ten days after starting $\mathrm{K}$ replacement therapy, serum $\mathrm{K}$ and $\mathrm{Cl}$ levels were normalized, and respiratory disorders improved $\left(\mathrm{PaO}_{2}, 82 \mathrm{mmHg} ; \mathrm{PaCO}_{2}, 44 \mathrm{mmHg}\right.$, under room air). Her transtubular $\mathrm{K}$ gradient was 4.2 at day 13 (serum K, $4.7 \mathrm{mmol} / \mathrm{l}$; urinary $\mathrm{K}, 46 \mathrm{mmol} / \mathrm{l}$; plasma osmolarity, $292 \mathrm{mOsmol} / \mathrm{kgH}_{2} \mathrm{O}$; urinary osmolarity, $670 \mathrm{mOsmol} / \mathrm{kgH}_{2} \mathrm{O}$ ). She was finally transferred back to the nursing home on the 14th hospital day under oral K supplementation. At discharge, the U-waves had disappeared and the 
corrected QT interval was normalized on electrocardiogram. K supplementation was stopped 2 months after discharge and serum $\mathrm{K}$ remained normal at 3 months after discharge (plasma renin activity, $0.6 \mathrm{ng} / \mathrm{ml} / \mathrm{h}$; plasma aldosterone concentration, $34.9 \mathrm{pg} / \mathrm{ml}$ ).

\section{Discussion}

There are a variety of differential diagnoses for hypokalemia with metabolic alkalosis [10]. These disorders are usually induced by increased mineralocorticoid activity, such as in Cushing syndrome, deoxycorticosterone-producing tumors, apparent mineralocorticoid excess syndrome, Bartter syndrome, Gitelman syndrome, Gordon syndrome, Conn syndrome, reninoma, and renal artery stenosis. In the present case, the patient showed hypokalemia, metabolic alkalosis, high urinary K excretion with high transtubular K gradient, hypertension with peripheral edema, suppressed renin-angiotensin-aldosterone axis, and a history of yokukansan use. Her adrenal and thyroid functions were normal. These findings were consistent with pseudoaldosteronism, and the patient was successfully treated by the discontinuation of yokukansan and intravenous $\mathrm{K}$ replacement.

Pseudoaldosteronism as a licorice-induced complication is an important pathogeneses of hypokalemia and metabolic alkalosis. Pseudoaldosteronism usually presents as hypertension (sodium retention), high urinary $\mathrm{K}$ and $\mathrm{Cl}$ excretion, hypokalemia, metabolic alkalosis (hypochloridemia), and suppression of the renin-angiotensin-aldosterone system. Pseudoaldosteronism related to licorice is caused by its inhibition of $11 \beta$-HSD 2 activity, which converts active cortisol into inactive cortisone [11]. After licorice is metabolized into glycyrrhizin, glycyrrhizin blocks endogenous $11 \beta$-HSD2, leading to the increase in cortisol, which can equally stimulate mineralocorticoid receptors as well as aldosterone [12]. A variety of Chinese herbal medicines include licorice and, thus, have the potential to cause pseudoaldosteronism, as in the present case.

Yokukansan contains $4.5 \mathrm{~g}$ of licorice $7.5 \mathrm{~g}$ of yokukansan. Recent clinical studies have shown that yokukansan is effective in the treatment of BPSD [7-9]. Conventional treatments for BPSD, such as typical and atypical antipsychotic drugs, have various side effects, including impairment of cognitive function, somnolence, extrapyramidal symptoms, and gait disorders, and mortality is higher in elderly patients with dementia using typical or atypical antipsychotic drugs [13]. Yokukansan, therefore, represents an attractive and beneficial alternative, because it rarely causes serious side effects [7, 8]. However, as reported previously, hypokalemia is an important side effect, with an incidence rate of $6.6 \%$ for yokukansan, compared with $33 \%$ for shosaiko-to and shakuyaku-kanzo-to, respectively $[14,15]$. The incidence of hypokalemia depends on the daily dose of ingested licorice and the duration of the treatment, and its precise incidence, thus, remains undetermined. Although only premature atrial contractions and electrical findings related to hypokalemia were observed in the present case, the patient showed severe hypokalemia that can lead to lethal arrhythmia. Additionally, the numbers of patients with Alzheimer's disease are increasing as the social structure ages, and more elderly Japanese patients are, therefore, likely to be treated with yokukansan for BPSD, associated with the potential danger of developing pseudoaldosteronism. Physicians should, therefore, be aware of the potential of yokukansan to induce pseudoaldosteronism, and should monitor serum $\mathrm{K}$ and $\mathrm{Cl}$ levels closely to ensure that the signs of pseudoaldosteronism are not overlooked, especially in elderly patients.

Importantly, the current patient also developed respiratory acidosis related to hypokalemia. Metabolic alkalosis is usually accompanied by respiratory compensation to mitigate alkalosis; hypoventilation followed by hypercapnia decreases the blood $\mathrm{pH}$ level. However, the upper limit of $\mathrm{PaCO}_{2}$ in response to metabolic alkalosis is reported to be lower than $60 \mathrm{mmHg}$, while $\mathrm{PaCO}_{2}$ in the present case was $60.5 \mathrm{mmHg}$, with a maximum of $61.5 \mathrm{mmHg}$ on the second hospital day. The value of $\mathrm{PaCO}_{2}$ could, thus, not be explained by simple respiratory compensation in response to metabolic alkalosis. Furthermore, the patient suffered from hypoventilation, probably related to respiratory muscle weakness, which was aggravated by sustained and severe hypokalemia. These results suggest that the patient developed both metabolic alkalosis and respiratory acidosis. This case, thus, emphasizes the importance of considering a combined acid-base disorder in patients with pseudoaldosteronism and severe hypokalemia.

It remains unclear as to why only a limited number of cases develop pseudoaldosteronism, even though many people use Chinese herbal medicines containing licorice. The development of pseudoaldosteronism may depend on various factors. Recent clinical studies have revealed that hypertension, old age, and dosing period are risk factors for developing licorice-induced pseudoaldosteronism [16, 17]. Fujiwara et al. [18] reported that the daily dose of glycyrrhizin which induces pseudoaldosteronism ranges from 20 to $586 \mathrm{mg}$, and the reported duration from 6 days to 15 years, showing a great variation in the sensitivity of the mineralocorticoid regulation system. Yasue et al. [5] also reported the possibility that concomitant inflammation can aggravate pseudoaldosteronism through endogenous cortisol production. In the present case, the patient was very elderly, and the duration of yokukansan use was 6 months. Besides, she developed urinary tract infection at the time of admission. These concomitant conditions in the present 
case might have promoted the development of pseudoaldosteronism. Hence, further large-scale studies are required to investigate the factors that facilitate the development of pseudoaldosteronism.

Complications related to yokukansan use range from mild to fatal, and side effects include muscle weakness, paralytic ileus, polyuria, and rhabdomyolysis. As in the present case, constipation may be a mild side effect related to yokukansan treatment, attributable to hypokalemiainduced hypoactive bowel. More recently, the Ministry of Health, Labour and Wealth (Japan) has reported several cases of severe liver dysfunction and lethal interstitial pneumonia, and has recommended the careful use of yokukansan. Hence, although yokukansan is safe in most cases, it should be used with caution, and patients should be monitored carefully for possible complications.

In summary, we present here the case of an elderly patient treated with yokukansan, a Chinese herbal medicine containing licorice, who developed pseudoaldosteronism presenting as severe hypokalemia, metabolic alkalosis, and respiratory acidosis. Yokukansan can induce pseudoaldosteronism by inhibiting endogenous $11 \beta$-HSD2, and nephrologists should, thus, consider the potential involvement of this drug when they encounter hypokalemic elderly patients with dementia, in order to avoid serious complications such as lethal arrhythmia and cardiac failure.

Acknowledgments We thank Edanz Editing (http://www.edanz editing.co.jp) for the careful reading and editing of the manuscript.

Conflict of interest All authors have declared no competing interest.

\section{References}

1. Schlanger LE, Bailey JL, Sands JM. Electrolytes in the aging. Adv Chronic Kidney Dis. 2010;17:308-19.

2. Kamel KS, Quaggin S, Scheich A, Halperin ML. Disorders of potassium homeostasis: an approach based on pathophysiology. Am J Kidney Dis. 1994;24:597-613.

3. Ben Salem C, Hmouda H, Bouraoui K. Drug-induced hypokalaemia. Curr Drug Saf. 2009;4:55-61.

4. Lin SH, Halperin ML. Hypokalemia: a practical approach to diagnosis and its genetic basis. Curr Med Chem. 2007;14:1551-65.
5. Yasue H, Itoh T, Mizuno Y, Harada E. Severe hypokalemia, rhabdomyolysis, muscle paralysis, and respiratory impairment in a hypertensive patient taking herbal medicines containing licorice. Intern Med. 2007;46:575-8.

6. Farese RV Jr, Biglieri EG, Shackleton CH, Irony I, GomezFontes R. Licorice-induced hypermineralocorticoidism. N Engl J Med. 1991;325:1223-7.

7. Hayashi Y, Ishida Y, Inoue T, et al. Treatment of behavioral and psychological symptoms of Alzheimer-type dementia with Yokukansan in clinical practice. Prog Neuropsychopharmacol Biol Psychiatry. 2010;34:541-5.

8. Okahara K, Ishida Y, Hayashi Y, et al. Effects of Yokukansan on behavioral and psychological symptoms of dementia in regular treatment for Alzheimer's disease. Prog Neuropsychopharmacol Biol Psychiatry. 2010;34:532-6.

9. Mizukami K, Asada T, Kinoshita T, et al. A randomized crossover study of a traditional Japanese medicine (kampo), yokukansan, in the treatment of the behavioural and psychological symptoms of dementia. Int J Neuropsychopharmacol. 2009;12: 191-9.

10. Pant P, Nadimpalli L, Singh M, Cheng JC. A case of severe hypokalemic paralysis and hypertension. Licorice-induced hypokalemic paralysis. Am J Kidney Dis. 2010;55:A35-7.

11. Stewart PM, Wallace AM, Valentino R, Burt D, Shackleton $\mathrm{CH}$, Edwards CR. Mineralocorticoid activity of liquorice: 11-betahydroxysteroid dehydrogenase deficiency comes of age. Lancet. 1987;2:821-4.

12. Arriza JL, Weinberger C, Cerelli G, et al. Cloning of human mineralocorticoid receptor complementary DNA: structural and functional kinship with the glucocorticoid receptor. Science. 1987;237:268-75.

13. Schneider LS, Dagerman KS, Insel P. Risk of death with atypical antipsychotic drug treatment for dementia: meta-analysis of randomized placebo-controlled trials. JAMA. 2005;294:1934-43.

14. Iwasaki K, Kosaka K, Mori H, et al. Open label trial to evaluate the efficacy and safety of Yokukansan, a traditional Asian medicine, in dementia with Lewy bodies. J Am Geriatr Soc. 2011;59:936-8.

15. Homma M, Ishihara M, Qian W, Kohda Y. Effects of long term administration of Shakuyaku-kanzo-to and Shosaiko-to on serum potassium levels. Yakugaku Zasshi. 2006;126:973-8 (Article in Japanese).

16. Ferrari P, Sansonnens A, Dick B, Frey FJ. In vivo 11beta-HSD-2 activity: variability, salt-sensitivity, and effect of licorice. Hypertension. 2001;38:1330-6.

17. Sigurjonsdottir HA, Manhem K, Axelson M, Wallerstedt S. Subjects with essential hypertension are more sensitive to the inhibition of 11 beta-HSD by liquorice. J Hum Hypertens. 2003; 17:125-31.

18. Fujiwara Y, Kikkawa R, Nakata K, Kitamura E, Takama T, Shigeta Y. Hypokalemia and sodium retention in patients with diabetes and chronic hepatitis receiving insulin and glycyrrhizin. Endocrinol Jpn. 1983;30:243-9. 